\title{
BIBLIOGRAFIA
}

\section{Bibliografía de las Obras de Augusto d'Halmar}

Se puede decir que la labor de escritor de Augusto d'Halmar comienza a los $x 6$ años. Durante los 50 años siguientes, hasta su muerte en I950, colaboró en un gran número de revistas y periódicos en Chile y en otras repúblicas americanas así como en España y en Francia. Aunque no nos faltan compilaciones de los títulos de los libros de don Augusto, es bastante difícil encontrar listas de sus artículos, los cuales representan una gran parte de su obra total.

Recientemente ha habido un resurgimiento en el interés por el autor chileno y por la revaloración de su obra. Para facilitar el estudio de d'Halmar por medio de sus artículos, hemos preparado esta bibliografia. La lista no intenta ni tiene la pretensión de ser completa en su forma actual, puesto que no hemos incluido ningún artículo de los muchos publicados en Europa, los cuales estamos juntando. Además, seguramente faltan algunos artículos publicados en las Américas, aunque en muchos casos éstos no pasan de ser copias de artículos aqui mencionados.

A pesar de eso creemos que la presente sirve como base de investigaciones para los que quisieran proseguir el estudio del "Almirante del Buque Fantasma" por medio de su gran obra periodística. Hemos creído conveniente incluir en la primera parte una lista de los libros de d'Halmar publicados en Chile, en sus varias ediciones. La segunda parte contiene divisiones dispuestas alfabéticamente por títulos de revistas, y dentro de cada sección, por fecha de la publicación del artículo. Si las revistas o los periódicos no son chilenos, o si hay posibilidad de que se confundan los títulos, hemos apuntado el nombre de la ciudad en que se publican. 


\section{Libros Publicados en Chile}

Los alucinados. Santiago de Chile: Ediciones Ercilla, 1935.

Amor, cara y cruz. Santiago de Chile: Ediciones Ercilla, I935.

Capitanes sin barco. Santiago de Chile: Ediciones Ercilla, I934.

Carlos $V$ en Yuste. Santiago de Chile: Sociedad de Escritores de Chile, I945.

Cristián y yo. Santiago de Chile: Editorial Nascimento, I946.

Curso de oratoria en doce lecciones. Santiago de Chile:: Editorial Cruz de Triana, 1949.

Gatita, y otras narraciones. Santiago de Chile: Ediciones Ercilla, r935.

Juana Lacero. Santiago de Chile: Imprenta Turín, r9o2.

Juana Lucero. Santiago de Chile: Editorial Nascimento, I952.

La lámpara en el molino. Santiago de Chile: Imprenta New York, I9I4.

La lámpara en el molino. Santiago de Chile: Ediciones Ercilla, r935.

Lo que no se ba dicho sobre la actual revolución española. Santiago de Chile: Ediciones Ercilla, I934.

La Lucero (Juana Lucero). Santiago de Chile: Ediciones Ercilla, I934.

La Mancha de don Quijote. Santiago de Chile: Ediciones Ercilla, I934.

Mar, "Sojoeroman". Santiago de Chile: Editotial Cruz del Sur, I943.

Nirvana (Cuadernos de bitácora) Viajes por Occidente, Oriente y Extremo Oriente. Santiago de Chile: Ediciones Ercilla, 1935.

Palabras para canciones, Poemas en tono menor. Santiago de Chile: Editorial Orbe, I942.

La pasión y Muerte del cura Deusto. Santiago de Chile: Editorial Nascimento, 1938.

Rubén Dario y los americanos en París. Santiago de Chile: Prensas de la Universidad de Chile, I94I.

La sombra del bumo en el espejo. Santiago de Chile: Ediciones Ercilla, I934.

Los 21. Santiago de Chile: Editorial Nascimento, 1948. 


\section{ARtículos}

Andina [Valparaíso]

"Los orgullosos", septiembre I909; "I4 de Julio", julio, I9ıo.

\section{Antártica}

"La provincia en Chile", septiembre, I946; "Nuestro Santiago", noviembre, I946.

\section{Atenea [Universidad de Concepción]}

"J. Edwards Bello y su novela española", XI (julio r929), pp. 497-500; "Una crónica anacrónica", XIV (noviembre, 1930), pP.570-578; "Simón, el mago libertador", XVI (julio, r93r), pp. I62-I72; "El poeta nacional", XIX (enero, I932), PP. 2I-30; "Juan Francisco", XXIII (abril, I933), pp. 243-246; "El castillo desmantelado y las huertas de Camacho", XXVII (julio, I934), pp. 76-85; "Un discurso de d'Halmar", XXVIII (noviembre, I934), pp. I62-I65; "Leonardo Pena", XXX (mayo, x935), pp. II7-r24; "Quito uno y quedan dos", XXXII (noviembre, I935), pp. 25026r; "Un zeppelín en el puerto", XXXVIII (mayo, I937), pp. I47-I56; "Los sueños cambiados", XXXVIII (julio, I937), Pp. 2 I25; "Andemos para no llegar", XL (diciembre, I937), pp. 4I242I; "De mi último viaje", III (abril, I938), pp. 35-45; "Un chileno que vuelve", LIII (julio, I938), pp. 3I-39; "Cante jondo", LIV (noviembre, I938), Pp. I72-I82; "Tres amigos que se nos van", LV (enero, I939), pp. 78-84; "Números", LXIII (enero, I94I), pp. 44-50; "Misa de requiem", LXXIX (enero-febrero, r945), pp. 5-20; "El maestro Gordon, mi condiscípulo", LXXX (mayo, I945), pp. I08-Ir2; "Teatro de cámara", LXXXI (agostoseptiembre, I945), Pp. I63-I82; "Uno-ninguno", LXXXIII (enero, I946), pp. 28-3I; "Melfi y los otros y nosotros", LXXXIII (marzo, т946), pp. 306-307; "Siluetas animadas; el último paseo de Goya en Burdeos", LXXXIV (abril, 1946), pp. 67-70; "El neurocirujano Asenjo", LXXXV (septiembre-octubre, I946), pp. 2 Io. 2I4; "La Cenicienta sin príncipe", XC (septiembre-octubre, I948), pp. I96-200; "Cuento cómo cuento un cuento", XC (septiembreoctubre, I948), PP. 8-I9; "El París balzaciano del 900", XCIV (julio-agosto, I949), PP. I2-20. 
Ateneo de Honduras [Tegucigalpa]

"Vaga y lejana vuelve", IV, - pp. I633-I638; "Sabiduría práctica", V, pp. 202I-2022; "Nuestra misión", V, - pp. 2022- 2023 "Innominado", V, pp. $2023 \cdot 2024$.

\section{La Bandera de Chile}

"Poquita cosa", 2x de diciembre, I902; "Pedro Antonio González", 9 de agosto, 1903.

\section{Cbile Ilustrado}

"Cuando la noche llega", enero, I904; "Un extranjero", marzo, I904; "Ernesto Molina", julio, I904; "Los orgullosos", octubre, 1904; "Quiromancia", enero I905; "Víctor Domingo Silva. Recuerdos íntimos", enero, I905, "El día de la abuelita", febrero, I905; "El país del sueño"; marzo, I905; "El amigo íntimo", juniojulio, I905; "Mamá Dotea", noviembre-diciembre, I905.

\section{El Cojo Ilustrado [Caracas]}

"El alma del violín", XII, pp. 252-255.

El Diario Ilustrado [Santiago de Chile]

"El jardin de San Carlos en la Coruña", rs de diciembre, r928; "Perros y gatos", 4 de marzo, I929.

\section{Los Diez}

"Gatita", No. 2 de I9I6.

\section{La Hora [Santiago de Chile]}

"La pampa a vista de intelectual", 25 de junio, I935; "La pampa a vista de hombre", 27 de junio, I935; "La pampa a vista de ojo", 29 de junio, I935; "La pampa a ojo de buen cubero", I de julio, r935; "La pampa a la vista y al desnudo", 3 de julio, r935; "Iniciaciones. La cadena de la suerte", 6 de julio, I935; "Iniciaciones. Los veteranos de la Plaza de Armas", 8 de julio, r935; "Iniciaciones. Un coleguita", to de julio, I935; "Iniciaciones. Uno y trino", 13 de julio, x935; "Nirvana. Capítulo del libro en prensa...", 44 de julio, 1935; "Iniciaciones. Un viejo teatro nuevo", I5 de julio, I935; "Iniciaciones. Azaña", I7 de julio, I935; "Iniciaciones. Mercedes", 20 de julio, I935; "Iniciaciones. Lipschutz", 22 de julio, I935; "Iniciaciones. La Alameda de las Delicias", 25 de 
julio, I935; "Iniciaciones. La moneda", 28 de julio, I935; "Iniciaciones. Simpatía sismológica", 30 de julio, I935; "Iniciaciones. El río", 2 de agosto, I935; "Significativo homenaje se rindió a la memoria de Magallanes Moure", 4 de agosto, I935; "Iniciaciones. Política de fondo y no de forma", 5 de agosto, I935; "Iniciaciones. La pena de muerte", 7 de agosto, ... I935; "Iniciaciones. Tres amigos de 'María Elena' y otro que tal", 9 de agosto, I935; "Iniciaciones. El centro en otras partes", I I de agosto, I935; "Iniciaciones. Cuarteto", I3 de agosto, I935; "Iniciaciones. Madrileñas. Verbenas", I5 de agosto, I935; "Iniciaciones. El roto chileno", I9 de agosto, r935; "Madrileñas. 'Mi Madrid'", 22 de agosto, I935; "Iniciaciones. Nuestro centro", 23 de agosto, I935; "Iniciaciones. Una exposición", 26 de agosto, I935; "Iniciaciones. El último profeta", 28 de agosto, r935; "Iniciaciones. Madrileñas. Pregones", 3 I de agosto, I935; "Iniciaciones. El hambre santa", 2 de septiembre, I935; "Iniciaciones. El aventurero y la aventura", 4 de septiembre, I935; "Madrileñas. El Rastro", 6 de septiembre, I935; "Iniciaciones. 'El canario de Arrabel" ", 9 de septiembre, 1935; "Iniciaciones. Vida de perros", II de septiembre, I935; "Iniciaciones. Aires de España", I3 de septiembre, I935; "Iniciaciones. El municipal", Is de septiembre, r935; "Iniciaciones. El águila y la serpiente", I7 de septiembre, I935; "Iniciaciones. E1 dieciocho", I9 de septiembre, I935; "Iniciaciones. Balmaceda", 2 I de septiembre, I935; "Iniciaciones. Otra historia de perros", 23 de septicmbre, r935; "Arboles", 28 de septiembre, I935; "Iniciaciones. Las bellezas de Santiago", 30 de septiembre, I935; "Iniciaciones. El judío errante", 2 de octubre, I935; "Iniciaciones. "Vida noctámbula", 5 de octubre, I935; "Iniciaciones. Hispanismo y anti-hispanismo", 7 de octubre, I935; "Iniciaciones. Gloria y vanagloria", 9 de octubre, I935; "Iniciaciones. El gato feliz", I5 de octubre, I935; "Iniciaciones. Conferencias", I8 de octubre, r935; "Iniciaciones. "No somos como los demás",, 20 de octubre, I935; "Iniciaciones. Boites de nuit", 24 de octubre, I935; "Iniciaciones. Provincias", 27 de octubre, I935; "Iniciaciones. Jubilar", 30 de octubre, I935; "Iniciaciones. Niños", 3 de noviembre, 1935; "Iniciaciones. Los fieles difuntos", 6 de noviembre, I935; "Iniciaciones. Horóscopo", 9 de noviembre, 1935; "Aquel noviembre", I2 de noviembre, I935; "Iniciaciones. Lota", I5 de noviembre, I935; "Ini- 
ciaciones. Madrid en casa", 23 de noviembre, r935; "Iniciaciones. El cantar de los cantares", 28 de noviembre, I935; "Iniciaciones. Americanos en España", I de diciembre, I935; "Iniciaciones. El apostadero naval", 3 de diciembre, I935; "Iniciaciones. Arpa y guitarra", 6 de diciembre, r935; "Iniciaciones. Compañía infantil", 8 de diciembre, I935; "Iniciaciones. I3", I3 de diciembre, I935; "Iniciaciones. Navidades". 25 de diciembre, I935; "Iniciaciones. Nuevos años viejos". I de enero I936; "Iniciaciones. Puerto y puertas", 4 de enero, I93.6; "Iniciaciones. Los reyes se van", 6 de enero, I936; "Iniciaciones. Valle Inclán", to de enero, I936; "Iniciaciones. Un hombre de una pieza", i I de enero, I936; "Iniciaciones. Barcos", I9 de enero, I936; "Iniciaciones. Puerto en sábado", 24 de enero, I936; "Iniciaciones. Una plaza ireemplazable", 29 de enero, I936; "Iniciaciones. Montcalm", 2 de febrero, I936; "Iniciaciones. Torpederas", 5 de febrero, I936; "Iniciaciones. "Cine de Finlandia" ", 9 de febrero, r936; "Iniciaciones. Veinte años después", I4 de febrero, r936; "Iniciaciones. La Chaya", I9 de febrero, 1936; "Iniciaciones. Alta política", 24 de febrero, I936; "Iniciaciones. La paz de la tarde", 28 de febrero, I936; "Iniciaciones. Quintero", 2 de marzo, I936; "Iniciaciones. Columbus", 5 de marzo, I936; "Iniciaciones. La rueda de oro", in de marzo, I936; "Iniciaciones. Fatum", I 6 de marzo, I936; "Iniciaciones. La rueda clavada", I8 de marzo, r936; "Iniciaciones. Diversión y alegria", 2 I de marzo, I936; "Iniciaciones. Los cerros", 25 de marzo, I936; "Iniciaciones. Cosas impolíticas", 28 de marzo, 1936; "Iniciaciones. Mares de otoño", 2 de abril, I936; "Iniciaciones. Callegeando", 7 de abril, I936; "Iniciaciones. La ciudad del fuego", i I de abril, I936; "Iniciaciones. República española", I5 de abril, I936; "Iniciaciones. De otro tiempo", I8 de abril, r936; "Iniciaciones. Entierros en el destierro", 23 de abril, I936; "Iniciaciones. El bar de lo imprevisto", 26 de abril, 1936; "Iniciaciones. El cañonazo y la hora", 29 de abril, I936; "Iniciaciones. Gérmenes de paz", 2 de mayo, I936; "Iniciaciones. Monaguillos", 4 de mayo, I936; "Iniciaciones. La palabra de oro", 7 de mayo, I936; "Iniciaciones. Si vis pacem...", I I de mayo, I936 "Iniciaciones. Tótem y tabú", I6 de mayo, 1936; "Iniciaciones. En la tierra del agua", 2 I de mayo, 1936; "Iniciaciones. La radio", 23 de mayo, I936; "Iniciaciones. Monsicur Regnier", 27 de mayo, 1936; "Iniciaciones. Una suerte de "Affaire" ", I de julio, I936; "Iniciaciones. ¿A quién encarna 
Charlot?", 4 de junio, I936; "Iniciaciones. El loco del pueblo", 9 de junio, I936; "Iniciaciones. Disparates cuerdos", I8 de junio, I936; "Iniciaciones. Benigno", 22 de junio, I936; "Iniciaciones. La muerte de un vagabundo", 26 de junio, 1936; "Iniciaciones. '. . Entre junio y julio...'", 29 de junio, I936; "Iniciaciones. La procesión en el mar", 2 de julio, r936; "A telón corrido", ro de julio, r936; "Iniciaciones. Playancha", I3 de julio, I936; "Iniciaciones. Una anécdota", I6 de julio, I936; "Iniciaciones. Cartas atrasadas", 20 de julio, I936; "Faenas del puerto", 24 de julio, I936; "Iniciaciones. La bailarina y su pueblo", 27 de julio, I936; "Iniciaciones. Pretorianos", 3 r de julio, 1936; "Iniciaciones. Estampas santiaguinas", 3 de agosto, I936; "Iniciaciones. Pájaros de antaño", 5 de agosto, I936; "Iniciaciones. Cádiz", 2 de septiembre, I936; "Sobre el tapete rojo", 5 de septiembre, r936; "Iniciaciones. Bodas porteñas", Io de septiembre, I936; "Iniciaciones. El milagro de subsistir", I7 de septiembre, r936; "Iniciaciones. Un hombre, un exhombre y dos Españas", 2 I de septiembre, I936; "Iniciaciones. Zaragoza", 25 de septiembre, r936; "Iniciaciones. Los enemigos de España", x de octubre, I936.

\section{Ideales [Concepción]}

"Zuzú", 3 de mayo, I9r5; "La última carta", 3I de julio, r9r5.

\section{La Ilustración [Santiago de Chile]}

"Prólogo de Juana Lucero, novela en prensa de Augusto Thomson", Tercera semana de agosto, I902; "Historia de la luna paseadora y las cuatro Marías", Cuarta semana de agosto, I902; "Poquita cosa", Tercera semana de diciembre, r9o2.

\section{Instantáneas de Luz y Sombra}

"Pot-pourri", 9 de septiembre, r900; "Diana!" r6 de septiembre, I900; "Pot-pourri", 23 de septiembre, I900; "La abuelita", 30 de septiembre, I900; "Potpourri", 7 de octubre, r9o0; "Teatros", I4 de octubre, I900; "Teatros", 2 I de octubre, r900; "Arte en el salón de I900", 5 de noviembre, I900; "Arte en el salón de I900", I8 de noviembre, I900; "Arte en el salón de r900", 25 de noviembre, I900; "Pot-pourri", I2 de diciembre, I900; "El gran encantador", " 6 de diciembre, I900; "Miniaturas. Imposible", 25 de diciembre; I90o; "El cuento de Año Nuevo. Toda la dicha", I de 
enero, r90x; "Arte. En el taller de Ernesto Molina", 27 de enero, rgor; "El crepúsculo de los soles. (The Queen is dead.)", 27 de enero, I90I; "El crepúsculo de los soles. ¡Verdi ha muerto!", 3 de febrero, Igor; "Don Miguel Eyzaguirre", I7 de febrero, I9or; "Miniaturas. II. Mi canción", I7 de febrero, r9or; "Correspondencia porteña", 24 de febrero, r9or; "Vida de puerto", 3 de marzo, I90r; "Pot-pourri", ro de marzo, I90I; "Los 2I. Estudios sobre artistas. I. Virginio Arias", I7 de marzo, r90r; "Los 2r. Estudios sobre artistas. II. Pedro A. González", 7 de abril, I90r; "Los 2 r. Estudios sobre artistas. III. Alfredo Valenzuela Puelma", 2 I de abril, I90r; "Los 2r. Estudios sobre artistas. IV. Luis Orrego Luco", 5 de mayo, I90r; "Los 2т. Estudios sobre artistas. V. Ennesto Molina", I 2 de mayo, I90x; "Los 2I. Estudios sobre artistas. VI. Nicanor Plaza", 2 de junio, I90r; "Los 2r. Estudios sobre artistas. VII. Diego Dublé Urrutia", I6 de junio, I90I; "Los 21 Estudios sobre artistas. VIII. Juan Francisco González", 23 de junio, I90I; "Los 2r. Estudios sobre artistas. IX. Emilio Rodríguez Mendoza", 7 de julio, I90r; "Los 2r. Estudios sobre artistas. X. Manuel Plaza Ferrand", I8 de agosto, I90r; "Gaviotas", I4 de abril, I901; "De sensación", 28 de abril, I90I; "Alfredo Melossi", 26 de mayo, I90r; "Miniaturas. Zuzú", 9 de junio, I90I; "La rapiña", 30 de junio, rgor; "Nuestros colaboradores. Guillermo Labarca Hubertson", 30 de junio, I90I; "Friedenthal", 4 de agosto, I90I; "El día de la abuelita", I I de agosto, I90I; "Carlos Morla, íntimo", 25 de agosto, I90r; "Los sentimentales", 8 de septiembre, I90r; "El último sobreviviente de la Independencia", 22 de septiembre, I90I; "Arte. La exposición de [Pedro] Lira", 6 de octubre, I90I; "El salón de I90I", 27 de octubre, I90I; "El salón de I90I", 3 de noviembre, I90I; "El salón de I90I", ro de noviembre, I90I; "El salón de r90x", I7 de noviembre, I90r; "Arte. En el salón de I90r", 24 de noviembre, I90x; "El cuento de difuntos. La muerta", 3 de noviembre, Igor; "La última carta", 24 de noviembre, I90I; "El retrato al pastel", 8 de diciembre, I90I; "Alfonso Daudet", I5 de diciembre, I90I; "Predestinados", I5 de noviembre, I90I; "El cuento de Noche Buena. Junto al brasero", 29 de diciembre, I90I.

Letras [Santiago de Chile]

"Hora de Lubicz Milosz", mayo, r928; "Primer viaje", agosto, 1928; "La Gran Esfinge", agosto, I928; "París", agosto, I928; 
"Navidad en el mar", agosto, I928; "Barco que pasa", agosto, ... 1928; "Ultimo viaje", agosto, I928; "Loti y la casa del recuerdo", julio, r929; "La patria de los artistas", septiembre, I929.

\section{La Lira Cbilena [Concepción]}

"Poquita cosa", 2 I de diciembre, r902; "Los orgullosos", abril, I903; "Un patricio, Don Rafael Victorino Garrido", 27 de diciembre, I903; "Miniaturas. Imposibles", 6 de marzo, I904, "Hablo conmigo", 27 de marzo, I904; "Nuestra sombra", 5 de junio, r904.

\section{Los Lanes de La Tarde [Santiago de Chile]}

"Vida de Cómicos, escenas del teatro", 24 de abril, I899; "La vieja tía, para Roberto Alarcón Lobos", I de mayo, I899; "Una vida", I2 de junio, I899; "A la buena de Dios", 26 de junio, I899; "La canalla", Io de julio, I899; "Lo temido", 24 de julio, I899; "La abuelita", 2I de agosto, I899; "Sin hogar", 9 de octubre, I899; "Meditaciones", 23 de octubre, I899: "La profeșa", 30 de octubre, 1899; "La brega por el pan", I3 de noviembre, I899; "La culpable", 27 de noviembre, I899; "En decadencia", I8 de diciembre, I899; "Rapsodia. Del diario de una niña", I de enero, I900; "En plena bohemia. El sentimental", I5 de enero, I900; "Los telegramas", 5 de febrero, I900; "Sacrificio inútil", I9 de febrero, I900; "Pichiruche", I2 de marzo, I900; "Repiques festivos", I6 de abril, I900; "La noviecita", 23 de julio, r900; "Manuel Thomson O.", 30 de julio, I900; "Quintín Gorgojo", I de octubre, I900; "Los fracasados", 22 de octubre, I900.

\section{Luz y Sombra}

"Penumbras", 9 de junio, I900; "Corazones", I6 de junio, I900; "El Macul", 7 de julio, I900; "En la antesala", 7 de julio, ... r900; "Mamuel Thomson O.", 28 de julio, I900; "Teatros", 4 de agosto, I900; "Teatros", I8 de agosto, I900; "Pot-pourri", 25 de agosto, I900; "Pot-pourri", I de septiembre, I900.

El Mercurio [Santiago de Chile] "Plenilunio", 2 I de abril, I922; "Carta de d'Halmar al joven escritor chileno Luis Enrique Délano, sobre La niña de la prisión", 9 de diciembre, r929; "Carta de d'Halmar", r4 de junio, I934; "Recuerdo de Magallanes Moure - Palabras de d'Halmar", I 2 de agosto, 1934; "El mar de los chilenos", 30 de diciembre, I934. 
La Nación [Santiago de Chile]

"Iniciaciones. Mi Primera crónica", 29 de abril, x925; "Iniciaciones. Alonso Berruquette", 5 de mayo, I925; "Visiones: ciudades", I7 $_{7}$ de mayo, I925; "Vida de café", 3I de mayo, I925; "Carmen", 7 de junio, I925; "Catedrales", I4 de junio, I925; "El vicio impune de la lectura", 2 r de junio, 1925; "Durante la Semana Santa", 28 de junio, r925; "Héroes de ocasión", 5 de julio, I925; "Andersen", 19 de julio, I925, "Celebridades", 26 de julio, I925; "Alfareros", 2 de agosto, x925; "Liquidaciones sentimentales", I6 de agosto, 1925 ; "Trajes regionales", 30 de julio, I925; "Ibsen", 6 de septiembre, r925: "Retratos de niños", 20 de septiembre, r925; "Pierre Loti", 27 de septiembre, I925; "El demonio del Mediodía", 4 de octubre, 1925; "El niño Budha", 25 de octubre, I925; "Tumbas", I de noviembre, I925; "La exposición de artistas ibéricos", 8 de noviembre, I925; "Aventureros y desventurados", 15 de noviembre, 1925; "Arboles", 29 de noviembre, I925; Acuarelas del Amor, 6 de diciembre, I925; "Celeste Imperio", 6 de diciembre, I925; "Rojo y gualda", to de enero, I926; "Carta a un lector", I7 de enero, I926; "Muerte y transfiguración", 24 de enero, r926; "Compostela", I4 de febrero, I926; "La ciudad del árbol y del agua", 28 de febrero, I926; "Un chileno americano", I4 de marzo, I926; "Los Caneiros", 28 de marzo, I926; "Galicia y poesía", 4 de abril, ... 1926; "El vuelo sobre el mar", ir de abril, I926; "Actualidades de siempre", x8 de abril, 1926; "Fechas", 25 de abril, 1926; "Anecdotario", 2 de mayo, r926; "Damitas de café", 9 de mayo, r926; "El problema de la vida según Voronoff", I6 de mayo, I926; "La cárcel en la libertad", 6 de junio, I926; "Los niños, los viejos y la muerte", 20 de junio, 1926; "El San Francisco de los gatos", 18 de julio, I926; "Madrid, Señor y amigo", 25 de julio, I926; "Messer Gaster, el maestro del gusto", ro de octubre, I926; "Las noches del circo", 3 I de octubre, I926; "Todos quieren conocer su porvenir", I4 de noviembre, I926; "Avila, cuna de Teresa de Jesús", 6 de enero, I927; "Salamanca, sapientísima. Urbe teresiana", 23 de enero, 1927; "Iniciaciones. El príncipe indio en Europa", 6 de febrero, I927; "El agua y la salud", 27 de febrero, I927; "Iniciaciones. El cementerio de los Globe-Trotters", 27 de febrero, 1927; "Trasnochar", 6 de marzo, r927; "Iniciaciones. Una calle que es una sintesis de la raza", I3 de marzo, I927; "La casa donde hemos vivido", 20 de marzo, I927; "El silencio y la voz", r de abril, I927; 
"El rey de la vida", 3 de abril, I927; "El trabajo forzado", I7 de abril, I927; "Personajes inéditos", 30 de abril, I927; "El Jubileo de la segunda Roma", 22 de mayo, I927; "La bailarina malagueña en Asia", 5 de junio, I927; "Menos que ministro y más", I 2 de junio, I927; "Los actores de la vida", 3 de julio, r927; "Alba de Tormes", I4 de agosto, I927; "El rey", 2 I de agosto, I927; "La octava maravilla", 28 de agosto, I927; "La ciudad universitaria", 4 de septiembre, r927; "El Príncipe y el inválido", I8 de septiembre, I927; "El corazón no envejece", 2 de octubre, I927; "El notario delincuente", 9 de octubre, r927; "La invisibilidad de los cuerpos", 30 de octubre, I927; "Colón ante la leyenda y la historia", 6 de noviembre, I927; "Fútbol nacionalista", 20 de noviembre, I927; "Elogio de un pecado capital", 27 de noviembre, r927; "Un cuento alemán", 4 de diciembre, I927; "Cótdoba: La ciudad hispánica de linaje morisco", 25 de diciembre, I927; "Camino de la Mancha", I de enero, I928; "El retrato de don Quijote", 22 de enero, I928; "La obsesión de la muerte", 26 de enero, I928; "La rueda de la fantasía", 29 de enero, I928; "Las huellas franciscanas en España", 5 de febrero, I928; "Los sepultados en vida", I2 de febrero, r928; "En un lugar de la Mancha", I9 de febrero, I928; "La vendimia manchega", 26 de febrero, I928; "Los palacios de doña Dulcinea", 4 de marzo, I928; "La venta de Maritornes", r8 de marzo, I928; "Hacia el Toboso", I de abril, I928; "Granada", 8 de abril, I928; "Los molinos de viento", 27 de abril, I928; "Velando las armas", 29 de abril, I928; "Morir para renacer", to de noviembre, I928; "Barcerola", 22 de julio, I934; "El libro sobre Bello Eugenio Orrego Vicuña", 4 de agosto, I935; "Un libro porteño", 28 de mayo, I939; "Los hogares y las hogueras de España", I8 de junio, I939; "El poeta nacional de Lituania", 25 de junio, I939; "Recuerdos olvidados. I. Del 'Yoísmo' en las letras", 28 de junio, I939; "Recuerdos olvidados. II. Las primeras letras de un hombre de letras", 5 de julio, r939; "Recuerdos olvidados. III. Lecturas para toda la vida", I2 de julio, I939; "Recuerdos olvidados. IV. La abuela, la madre y las hermanas", I9 de julio, I939; "Vaga y lejana vuelve", 23 de julio, I939; "Recuerdos olvidados. V. Circo y teatro", 26 de julio, 1939; "Recuerdos olvidados. VI. Acordémonos de lo que no recordamos, o diez historias en una", 2 de agosto, r939; "Cristián en el Perú", 3 de agosto, I94I; "Recuerdos olvidados. VII. Fin de siglo en los fines del mundo", 9 de agosto, r939; "Recuerdos olvidados. 
VIII. Mañas, artimañas y patrañas", I6 de agosto, I939; "Recuerdos olvidados. IX. Adolescencia en un pueblo nuevo", 23 de agosto, I939; "Recuerdos olvidados. X. El aprendiz y los maestros", 30 de agosto, I939; "Recuerdos olvidados. XI. Las más amables anécdotas", 6 de septiembre, 1939; "Recuerdos olvidados. XII. Argumentos sintéticos", I3 de septiembre, I939; "Recuerdos olvidados. XIII. Gente conocida que empezamos a conocer", I7 de septiembre, I939; "Recuerdos olvidados. XIV. Antecedentes," 24 de septiembre, I939; "Recuerdos olvidados. XV. La edad ingrata", I de octubre, I939; "Recuerdos olvidados. XVI. La generación del 900", 8 de octubre, I939; "Recuerdos olvidados. XVII. Características criollas", $x_{5}$ de octubre, I939; "Recuerdos olvidados. XVIII. Las tertulias del 900", 22 de octubre, I939; "Recuerdos olvidados. XIX. Un gran amor", 29 de octubre, I939; "Recuerdos olvidados. XX. El Ateneo", 5 de noviembre, I939; "Recuerdos olvidados. XXI. Tiempos de premios y apremios", I2 de noviembre, I939; "Recuerdos olvidados. XXII. Amigos para toda la vida", i9 de noviembre, I939; "Recuerdos olvidados. XXIII. La tía sueca", 26 de noviembre, r939; "Recuerdos olvidados. XXIV. El Machitún", 3 de diciembre, I939; "Recuerdos olvidados. XXV. Las casas que hemos habitado", to de diciembre, I939; "Recuerdos olvidados. XXVI. Añejeces", 17 de diciembre, I939; "Recuerdos olvidados. XXVII. La ópera", 3 I de diciembre, r939; "Recuerdos olvidados. XXVIII. Números y letras", 7 de enero, I940; Recuerdos olvidados. XXIX. Modas y modales", I4 de enero, r940; "Recuerdos olvidados. XXX. Fechas", 30 de enero, I940; "Recuerdos olvidados. XXXI. Empieza el dieciocho", 28 de enero, 1940; "Recuerdos olvidados. XXXII. El dieciocho se acaba", I I de febrero, 1940; "Recuerdos olvidados. XXXIII. Prima Carmela", I8 de febrero, I940; "Recuerdos olvidados. XXXIV. Inquietudes", 25 de febrero, I940; "Recuerdos olvidados. XXXV. Preliminares Tolstoyanos", 3 de marzo, I940; "Recuerdos olvidados. XXXVI. La colonia Tolstoyana", 7 de abril, I940; "Recuerdos olvidados. XXXVII. No más hogar", I4 de abril, I940; "Recuerdos olvidados. ... XXXVIII. La vida se prosigue", 2 I de abril, I940; "Recuerdos olvidados. XXXIX. En San Bernardo", 28 de abril, I940; "Recuerdos olvidados. XI. El protector y el desconocido", 5 de mayo, 1940; "Recuerdos olvidados. XLI. Kouchits", I2 de mayo, r940; "Recuerdos olvidados. XLII. Los amigos: tres suicidios", ig de 
mayo, x940; "Recuerdos olvidados. XIIII. Los amigos: Robinet", 26 de mayo, 1940; "Recuerdos olvidados, XLIV. Los amigos: Dagoberto", 2 de junio, I940; "Recuerdos olvidados. XLV. I6 de agosto, x906", 9 de junio, I940; "Recuerdos olvidados. XLVI. Valparaíso en su elemento", I6 de junio, x940; "Recuerdos olvidados. XLVII. Un capítulo del diario de Cristián Delande", 23 de junio, I940; "Recuerdos olvidados. XLVIII. Pintores novecentistas", 30 de junio, I940; "Recuerdos olvidados. XLIX. Los escenarios, las obras y los artistas", 7 de julio, I940; "Recuerdos olvidados. L. Crímenes para argumentos y argumentos pata crímenes", I4 de julio, 1940; "Recuerdos olvidados. LI. La diplomacia. Las amigas. Colomba", 21 de julio, r940; "Recuerdos olvidados. LII. El amor de la partida", 28 de julio, I940; "Recuerdos olvidados. LIII. El "Oravia", Punta Arenas y la casa paterna", 4 de agosto, 1940; "Recuerdos olvidados, LIV. En el mar. Las columnas de Hércules o a las puntas del Viejo Mundo", II de agosto, I940; "Recuerdos olvidados. LV. Londres, el Año Nuevo de I908", т8 de agosto, I940; "Recuerdos olvidados. LVI. Un país que ya no es", 25 de agosto, I940; "Recuerdos olvidados. LVII. Una etapa de la vida parisiense", I de septiembre, I940; "Recuerdos olvidados. LVIII. Embrollos de época y que hacen época", 8 de septiembre, I940; "Recuerdos olvidados LIX. Paris, toujours Paris", 22 de septiembre, I940; "Recuerdos olvidados. LX. Camposantos", 29 de septiembre, I940; "Recuerdos olvidados. LXI. Suiza, 'Pierre de Coulevain", 9 de octubre, I940; "Recuerdos olvidados. LXII. Italia, una y única", I3 de octubre, 1940; "Recuerdos olvidados. LXIII. De Milán a Venecia por Cremona y Vetona", 20 de octubre, I940; "Recuerdos olvidados. LXIV. Tierra de agua", 27 de octubre, I940; "Recuerdos olvidados. LXV. Firenze", 3 de noviembre, I940; "Recuerdos olvidados. LXVI. Fiesole. Edmundo d'Amicis", to de noviembre, I940; "Recuerdos olvidados. LXVII. Arte florentino", I7 de noviembre, I940; "Recuerdos olvidados. LXVIII. Florencia, artística y popular", 24 de noviembre, I940; "Recuerdos olvidados. LXIX. Asís", I de diciembre, I940; "Recuerdos olvidados. LXX. Sobre las huellas del Pobrecito de Asís", 8 de diciembre, I940; "Recuerdos olvidados. LXXI. La ciudad eterna", I5 de diciembre, I940; "Recuerdos olvidados. LXXII. Roma", 22 de diciembre, I94.; "Recuerdos olvidados. LXXIII. Nápoles", 29 de diciembre, I940; "Re- 
cuerdos olvidados. LXXIV. Pompeya", 5 de enero, I94r; "El archipiélago", I2 de enero, I94x; "Hacia Grecia", x9 de enero, I94I; "De Esmirna a Constantinopla", 26 de enero, x94r; "Creciente Turco", 2 de febrero, I94r; "El Egipto", 9 de febrero, I94r; "El Cairo", I6 de febrero, I94I; "El Museo de los Faraones y sus tumbas y la Esfinge", 23 de febrero, I94I; "Giseh-El Nilo-Menfis" 2 de marzo, r94I; "Tebas, Assaun y Philae", 9 de marzo, r94I; "En las fronteras de los mundos", I6 de marzo, I94I; "El mar y los mares", 23 de marzo, I94I; "El barco", 30 de marzo, I94I; "La isla", 6 de abril, I94I; "En la India", I3 de abril, I94r; "El Ganges", 20 de abril, I94I; "Calcuta", 27 de abril, I94I; "La leyenda de Buda", Ir de mayo, I94I; "I. Billamangal", I8 de mayo, I94I; "II. Billamangal", 25 de mayo, I94I; "En la India francesa. I", I de junio, r94x; "En la India francesa. II", 15 de junio, I94I; "Un idilio chinesco", 22 de junio, r94r; "El grumete de a bordo", 29 de junio, I94I; "Otra vez en el viejo mundo", 6 de julio, x94I; "En la tierra del mar", I3 de julio, I94I; "Desandando mares", 20 de julio, I94I; "Cristián en el Perú", 3 de agosto, I94I; "En el imperio de los Incas y de los virreyes", Io de agosto, I94r; "Manú Kakehashi", I7 de agosto, I94I; "Rip, otros perros y algunos gatuperios", 24 de agosto, I94I; "Los desterrados sin vuelta", 7 de septiembre, I94I; "La Huaca y. los Huacos", I4 de septiembre, I94I; "Tejedoras de humo", 2 I de septiembre, I94I; "La tumba de coral", 5 de octubre, I94I; "La odisea de un vizcaíno", I2 de octubre, I94I; "Otras singladuras", 26 de octubre, I94I; "Chile hace un cuarto de siglo", 2 de noviembre, I94I; "Donde se sigue haciendo historia en pequeño", 9 de noviembre, I94r; "Una pasajera en un viaje", I6 de noviembre, r94I; "Cádiz", 23 de noviembre, I94I; "las provincias vascongadas", 7 de diciembre, I94I; "Delenda est Paris", I4 de diciembre, I94 $\mathrm{r}$; "Corresponsal en campaña", 2I de diciembre, I94I; "París azul", 4 de enero, I942; "Herido grave de guerra", I I de enero, I942; "La resurrección de Lázaro", x8 de enero, I942; "El armisticio", 25 de enero, I942; "Puente internacional", 8 de febrero, I942; "Madrid, señor y amigo", I5 de febrero, I942; "En Madrid tiene Ud. su casa", I de marzo, I942; "Madrid y el Guadarrama", 8 de marzo, 1942; "El monasterio y el monje", I5 de marzo, I942; "Rapsodia toledana", 22 de marzo, I942; "Toledo", 29 de marzo, I942; "La Segovia del 'Rey Salvaje" ", 5 de abril, I942; "Avila del Rey de los Santos y 
de los caballeros", x2 de abril, I942; "Salamanca", I9 de abril, 1942; "De Salamanca hacia Alba de Tormes", 26 de abril, 1942; "Alba de Tormes", 3 de mayo, 1942; "Valladolid", ro de mayo, I942; "Caput Castellae", I7 de mayo, x942; "Primer tiempo de una sinfonía andaluza", 24 de mayo, I942; "La Granada del Reino de Andalucía", 3 I de mayo, 1942; "Generalife, el reino de las aguas", $x_{4}$ de junio, I942; "Córdoba", 28 de junio, I942; "La gran Mezquita de la Zecca en Córdoba", 5 de julio, I942; "Los tres gajos de la Granada", 7 de julio, I942; "El misterio de la Semana Santa en Sevilla", I9 de julio, 1942; "El auto sacramental representado por un pueblo", 2 de agosto, 1942; "Catedral, obra de locos y hospital, obra de santos", I6 de agosto, I942; "La Carmona única y rara". 30 de agosto, I942; "La lámpara maravillosa", $x_{3}$ de septiembre, r942; "Por tierras gallegas", 27 de septiembre, I942; "La Coruña, ciudad de cristal y agua", II de octubre r942; "El jardín de San Carlos", $x$ de noviembre, I942.

Occidente [Santiago de Chile]

"Peregrinas. La Granada tripartita", noviembre, 1946.

\section{Del Pacifico}

"La gloria obscura", julio, I.935.

\section{Pánthesis}

"Una colaboración: Los conquistadores del sol", I de agosto, 1905.

\section{Pluma y Lápiz}

"Poquita cosa", 2 I de diciembre, r922.

\section{Primerose [Chillán]}

"Ternura", abril, I9r6.

Pro Arte

"Cartas íntimas", 23 de marzo, I950; "Cartas íntimas", 6 de abril, I950; "Cartas íntimas", I3 de abril, I950; "Cartas íntimas", 27 de abril, I950.

\section{Pro Cultura}

"Las hojas", No. 2 de abril, 1908. 
El Repertorio Americano [San José, Costa Rica]

"Zola", VIII, pp. 294-295; "Anderson", XI, pp. 4I-42; "Carta a Hugo Barbagelata de El Impiarcial, Montevideo", XXIV, pp. $x_{42-}$ I43, I48-I 5 I; "Decenario", XXVII, pp. 334-335.

Revista de Educación [Santiago de Chile]

"Laureles para aderezar la comida", abril, I944; "El buen cristiano que se llamó Cristián", julio, I944; "Leit Motiv", junio, I950; "La acción pasa en...", diciembre y octubre, 1956.

Sucesos [Santiago de Chile]

"Una pariente... lejana", 24 de febrero, I9I6; "Navidad en el mar", 4 de mayo, I9I6; "Los niños de ámbar y espuma", 8 de noviembre, 1928 .

\section{El Sur [Concepción]}

"El almanaque de los pronósticos", 4 de enero, I929; "El invierno de los pobres", r9 de mayo, r929; "La novela de un americano en España", I de septiembre, I929; "La patria de los artistas", I5 de septiembre, 1929; "Loti y la casa del recuerdo", I9 de septiembre, I929; "Tercera de preferencia", 30 de septiembre, I929; "La salud del cuerpo y del alma", 5 de octubre, I929.

\section{Todo el Mundo en Sintesis}

"Los intelectuales en la formación y deformación de la República española", 30 de octubre, x935; "Lerroux, R.I.P.", 6 de noviembre, I935; "La noche de los tiempos", I3 de noviembre, I935; "Azaña adportas", 20 de noviembre, I935.

\section{La Unión [Santiago de Chile]}

"Desde el mar", I de septiembre, I9I6; "De Cádiz. Un divino. Morales", 26 de septiembre, rgr6; "Córdoba", 3 de octubre, I9r6; "Impresiones de conjunto", I3 de octubre, 1916; "Desde Madrid. La Armería. El Rastro. Velásquez", to de noviembre, I916; "Sevilla. I. La catedral", 26 de noviembre, I9I6; "Sevilla. II. La Giralda. El Alcázar. Interiores árabes", 30 de noviembre, I9r6; "El Escorial", 3 de diciembre, I9x6; "Toledo. I. Por el Kantara y la Puerta del Sol. El Greco", 7 de diciembre, I9I6; "Toledo. II. La Catedral. Las Ruinas. El mesón del sevillano", to de diciembre, 
1916; "Nuestra España. (Conferencia dictada en la Asociación Latino-Americana de París)", I4 y I7 de diciembre, I9r6; "El país Vasco. De Bilbao a San Sebastián", 22 de diciembre, I9r6: "El París de la guerra", 27 de diciembre, I916; "La guerra y los teatros parisienses", 29 de diciembre, I9r6; "Los 'trucs' de París", 29 de mayo, I917; "Nuestra Señora de París", I4 de junio, I9r7; "El invierno de I9r7 en París", 24 de junio, I9I7; "La muerte de aquí y ahora", $x$ de julio, 1917; "La primavera en París", 25 de septiembre, 1917; "Vagando por París", 3 de octubre, 1917; "Desde París", 9 de octubre, 1917; "El hogar y la guerra", I8 y I9 de octubre, I9r7; "Desde París. Volando", Io de noviembre, I917; "El Creuzot. La ciudad del acero en donde se prepara la muerte", I5 de noviembre, I917; "II. El Creuzot. Las municiones de Francia. En la petite Verriere. Un marqués Luis XV", 22 de noviembre, I917; "Una existencia parisiense", 6 de diciembre, I917; "Los jatdines de Paris", I8 de enero, I9r8; "Las zozobras de París. Huyen. do de la luz", 3 de febrero, I9I8; "Desde París. Rodín", I9 de marzo, r918; "Los cementerios de París", 3 de abril, I9r8; "El frío de París", I8 de abril, I918; "El París musical", 20 de junio, I9I8; "El día a día de París", 8 de diciembre, I9I8.

\section{En Viaje}

"Valparaiso", octubre, I942; "Repiques de Navidad", diciembre, I944; "La finalización y la iniciación del año", enero, I945; "Un chileno en el Perú", abril, I945.

\section{Zig Zag [Santiago de Chile]}

"Alma blanca", I9 de febrero, I905; "Carta a mi hermano", is de marzo, I905; "El ideal", 26 de marzo, I905; "Por los caminos. Un entierro", 2 de abril, I905; "Novela de una novela", 25 de junio, I905; "Después del teatro", 5 de noviembre, rg05; "Coilipo", 25 de diciembre, I905; "Sebastopol", 4 de febrero, I906; "Davis", I8 de marzo, I906; "Las perlas negras", 25 de marzo, I906; "La fiesta del otoño", 29 de abril, I906; "Mi Jueves Santo", 15 de abril, I906; "Divagando", 22 de abril, I906; "Una ruptura", I3 de mayo, І906; "Mi cumpleaños", to de junio, I906; "La muerte de Ibsen", Io de junio, I906; "Alrededor de Loti", 24 de junio, I906; "Transeúnte", 8 de julio, ìgo6; "Transeúnte", 15 de julio, I906; "Cenicienta", 26 de agosto, I906; Números", I6 de septiem- 
bre, r906; "El abuelo", 30 de septiembre, I906; "Nuestra sombra", I8 de octubre, I906; "A rodar tierras", Almanaque de 1907 ; "Año Nuevo en Londres", II de octubre, I908; "Mi cumpleaños", I8 de abril, I9I4; "Treinta años", 23 de mayo, I9I4; "El tema del amor", I de agosto, I9I4; "Paseo", 3 de octubre, r9i4; "Mi maestro", I9 de agosto, I9I6; "El regreso", 4 de septiembre, I9I6; "Nuestra aya", 23 de septiembre, I9I6; "A bordo", 6 de octubre, r9r7; "Comulgantes", 3 de noviembre, I9I7; "País somali", 3 de noviembre, I9I7; "Pequeños pensamientos del destierro", 22 de junio, r9x8; "Traducción de d'Halmar: La Reina de Karomama, por Oscar de Lubicz Milosz", I9 de julio, I924; "Números", I9 de noviembre, I927; "Innominado", 28 de abril, I928; "Visión $y$ audición desvelada de la pampa", 2 de agosto, 1935. 